\title{
Can annual land use plan control and regulate construction land growth in China?
}

Article

Accepted Version

Creative Commons: Attribution-Noncommercial-No Derivative Works 4.0

Zhou, Y., Huang, X., Zhong, T., Chen, Y., Yang, H. ORCID: https://orcid.org/0000-0001-9940-8273, Chen, Z., Xu, G., Niu, L. and Li, H. (2020) Can annual land use plan control and regulate construction land growth in China? Land Use Policy, 99. 105026. ISSN 0264-8377 doi:

https://doi.org/10.1016/j.landusepol.2020.105026 Available at https://centaur.reading.ac.uk/95962/

It is advisable to refer to the publisher's version if you intend to cite from the work. See Guidance on citing.

Published version at: https://www.sciencedirect.com/science/article/pii/S0264837719321854

To link to this article DOI: http://dx.doi.org/10.1016/j.landusepol.2020.105026

Publisher: Elsevier

All outputs in CentAUR are protected by Intellectual Property Rights law, including copyright law. Copyright and IPR is retained by the creators or other copyright holders. Terms and conditions for use of this material are defined in the End User Agreement. 


\section{CentAUR}

Central Archive at the University of Reading

Reading's research outputs online 


\title{
Can annual land use plan control and regulate construction land growth in China?
}

\author{
Yan Zhou ${ }^{\mathrm{a}}$, Xianjin Huang ${ }^{\mathrm{bc}}$, Taiyang Zhong ${ }^{\mathrm{b}}$, Yi Chen ${ }^{\mathrm{b}}$, Hong Yang ${ }^{\mathrm{d}}$, Zhigang Chen $^{\mathrm{b}}$, \\ Guoliang $\mathrm{Xu}^{\mathrm{e}}$, Lede Niu ${ }^{\mathrm{a}}$, Hehui $\mathrm{Li}^{\mathrm{a}}$ \\ ${ }^{\text {a }}$ School of Tourism and Geographical Sciences, Yunnan Normal University, 768 Juxian \\ Avenue, Kunming, Yunnan Province 650500, China \\ ${ }^{\mathrm{b}}$ School of Geographic and Oceanographic Sciences, Nanjing University, 163 Xianlin \\ Avenue, Nanjing, Jiangsu Province 210023, China \\ ${ }^{c}$ The Key Laboratory of the Coastal Zone Exploitation and Protection, Ministry of Land and \\ Resources, Nanjing, Jiangsu Province 210023, China \\ ${ }^{\mathrm{d}}$ Department of Geography and Environmental Science, University of Reading, Reading, \\ RG6 6AB, UK \\ ${ }^{\mathrm{e}}$ School of Tourism and Urban Management, Jiangxi University of Finance and Economics, \\ Nanchang, Jiangxi, 310023 China
}

\section{Abstract}

Annual land use plan (ALUP) stands for the quota allocation of land converted to nonagricultural use, which has been in place since 1987 in China. Although the ALUP has been implemented for more than 30 years and has played an important role in China's nonagricultural land growth management, little has been done to assess the effect of its implementation. The purpose of this research is to evaluate the effect of the ALUP on controlling the growth of construction land in China. The province-level data on land use in China during the period of 2006-2013 were collected and then analyzed using panel data model. The results show that (1) the ALUP can effectively curb construction land growth, and the construction land decreased about 1721 ha with a $1 \%$ increment of the intensity of growth management. Construction land growth is closely related to the implementation intensity of the ALUP, which decreases 30,892 ha under strict implementation but increases an extra 181,451 ha with relaxed implementation; (2) the implementation effect of the ALUP shows significant differences between provinces, and the provinces of northwestern and eastern China show better performance than provinces from the southwest and central regions. National development strategy and region's differentiation land policy may have contributed to this phenomenon; (3) taking both the goal achievement and effectiveness into account, the implementation of the ALUP is described as effective though not completely successful; and (4) for more efficiency and success, the study proposes some suggestions on improving policy implementation in the future. 


\section{Introduction}

The rapid expansion of construction land has been a common phenomenon in the world (Seto et al., 2011; Angel et al., 2011; Liu et al., 2014a; Zhang et al., 2015). It is estimated that the global population will increase by $30-70 \%$ in this century (United Nations, 2014), which will further promote the growth of construction land. Since 1978, China has experienced unprecedented growth in economy and urbanization. Such a great change leads to the accelerated construction land growth, which becomes the major characteristic of land use changes in China (Liu et al., 2014). According to China's national land surveys, the area of construction land increased more than 6 million hectares during 2002-2012 (MLR (Ministry of Land and Resources), 2013a). The increasing amount of farmland and open space are occupied by construction use in urban fringe area, this expansion to the periphery is usually associated with suburban development, or urban sprawl. Urban sprawl is a phenomena widely found around the world. Extensive urban land expansion has caused many serious environmental, economic and social consequences (Johnson, 2001; Foley et al., 2005). The environmental issues of aggressive non-agricultural land growth have resulted in the loss of high quality arable land, higher landscape fragmentation, degradation of wetlands, air pollution, heat island effects, and reduced biodiversity (Bradshaw and Muller, 1998; Du et al., 2007; Scolozzi and Geneletti, 2012; Yang et al., 2014; Yang et al., 2016; Lu et al., 2018; Lu et al., 2020). Specially, the lager amount of high quality arable land loss have a threat to the food production and food security in many developing countries. Taking China as an example, from 1980s to 2010, the ratio of cultivated land converted to construction land account for about $60 \%$ of the total incremental non-agricultural land, during 2010-2015, this ratio increased even to approximately $67.5 \%$ (Liu et al., 2014b; Liu et al., 2018a). In addition, the rapid expansion of construction land growth has also caused housing shortage, traffic congestion, deterioration of central cities, low efficiency of municipal facilities, greater social inequality and others economic and social problems (Freilich and Peshoff, 1997; Burchell and Mukherji, 2003; Ewing, 2008; Schetke et al., 2012). This will cause disturbance and threats to regional ecology and sustainable development of the society and economy.

The above serious consequences call for growth management strategies to be taken to manage urban growth and protect farmland (Couch and Karecha, 2006; Alnsour, 2016). Currently, urban growth boundaries (UGBs) and greenbelts are the two main measures used to curb urban sprawl. UGBs are a dividing line that separate the urban built-up districts from surrounding agricultural land or open space districts. Only districts inner the boundary is allowed for construction use while areas outside will not be permitted for urban construction (Bengston et al., 2004; Anas and Rhee, 2006). The greenbelts define a barrier of physical area surrounding a city that should not be exceeded by urban growth (Bengston and Youn, 2006). Other strategies such as zoning, master plans, land use planning, land preservation programs, tax incentives and similar policy initiatives also have been proposed to curb the rapid nonagricultural land growth, preserve farmland and environmentally sensitive areas (Grant, 2009; Zhou et al., 2017; Cheng and Shaw, 2018). Different from many European countries and the U.S., China has adopted a up-bottom Planed Land Use System to regulate the nonagricultural land growth, which is carried out through the general land use planning (GLUP) and the annual land use plan (ALUP). Both of them work simultaneously to control the construction land rapid increase. In broad terms, the GLUP determines the total quantity of newly-increased construction land during a long period (usually 10-15years); while the ALUP decides the annual plan quotas of construction land depend on the GLUP. The ALUP is an important measure of the GLUP implementation because the goals of GLUP should be 
divided into several parts annually. Stands for the annual quota allocation of land converted to construction land, the ALUP also serves as an important basis for the approval of the nonagricultural use land conversion as well as project establishment and decision making of construction land. Therefore, the ALUP plays a prominent role in land management and has an irreplaceable position in the land control system.

Evaluation of growth management strategies implementation makes great sense in the policy implementation improvement. Therefore, many scholars have put efforts on evaluation effectiveness of growth management strategies such as UGBs, greenbelts and zoning (Rao et al., 2004; Munroe et al., 2005; Gennaio et al., 2009; Amati, 2016; Jurjevich et al., 2017). Lots of studies have found that UGBs and green belts did not effectively curb the expansion of construction land, but could slow the urban sprawl to a certain extent (Weitz and Moore, 1998; Bengston and Youn, 2006). As a comprehensive growth management tool, the impact of land use planning and regulation on development also attracted scholars' attention. Those researches mainly focused on the aspects of development control (Van der Vlist, 1998; Alexander, 2001; Farthing, 2001), urban sprawl (Razin, 1998; Halleux et al., 2012), exurbanization (Esparza and Carruthers, 2000), land fragment (Saizen et al., 2006; Kim and Pauleit, 2007), sustainable development (van Lier, 1998v; Rydin, 1998; Godschalk, 2004), land markets and housing prices (Bramley, 1993). Most studies have found that land use planning implementation has promoted land concentrated development, slowed development rates and promoted building density increasing within the urban boundaries, which has a positive effective in curbing urban sprawl and achieve sustainable development (Ali, 2008; Gennaio et al., 2009; Dempsey et al., 2017). However, some other studies have found that the planning and regulations have failed in controlling urban sprawl and regulating urban growth (Halleux et al., 2012; Sharifi et al., 2014). Whether these manage tools effectively control construction land growth still needs more comprehensive research. For China, it has absorbed the Land Use Plan Management as tools to manage the land use, while only a few research focused on its implementation effect evaluation. In fact, despite the construction land is strictly allocated and restricted by the central government, the actual increasing rate reach up to $12.43 \%$ from 2006 to 2013 while expected $7.65 \%$ according the land-use change surveys (SCC (State Council of China), 2008). So it's urgent to evaluate the impact of Land Use Plan Management policy implementation. Although there are some studies put their efforts on China's Land Use Plan Management, they mainly focused on evaluation the effect of GLUP, laws and regulations (Wang et al., 2009; Zhong et al., 2014a; Xu et al., 2015; Zhou et al., 2017), while the ALUP attracts scarce attention on its implementation effectiveness. In fact, the ALUP serves as one of the most important tools for China's construction land growth management, which determine the detailed land allocation each year, making it more operable. Therefore, it is necessary to evaluate the effectiveness of ALUP, which will not only provide a deeper insight into this land management strategy, but also supply some reference for further land allocation improvement and reform.

Process analyses and modelling methods such as Logistics regression analysis, econometrics model and Difference-in-Difference (DID) estimator have been utilized to evaluate the impact of land use planning on development. Logistics regression analysis is commonly used in the evaluation of land use planning where the dependent variable is a binomial categorical constant (" 1 " or " 0 "). Logistic regression analysis can determine the role and strength of the explanatory variable $\mathrm{x}$ to predict the probability of the occurrence of the dependent variable $\mathrm{y}$ (Zhong et al., 2012; Lv et al., 2015). Econometric models are applicable to the evaluation of the effect of the implementation of the overall land-use planning based on panel data at the province-wide or prefecture-level cities (Xu et al., 2015; Zhou et al., 2017). The method of Difference-In-Difference can effectively eliminate the heterogeneity and time-increasing 
heterogeneity of the individual before and after the implementation of the policy and strip off the net effect of the policy implementation shock on the individual, so it has been widely used in the evaluation. In the evaluation of the implementation of land use planning, there are significant differences between the land use conversion before and after the implementation of the land use plan. However, land use conversion is also affected by factors such as time, macroeconomics, and random interference. Simply comparing the differences in land-use conversion before and after the implementation of the land use planning cannot truly reflect the implementation effect of the plan. Therefore, DID is applicated to test whether land use planning has an impact on urban land development (Dempsey et al., 2017).This study assess the effect of ALUP on the control of construction land. The data includes continuous panel data of 31 provinces from 2006to 2013, with reference to existing research practices (Xu et al., 2015; Zhou et al., 2017) that suitable for analysis of measurement models. Therefore, this paper adopts econometric model to systematically and comprehensively evaluate the effect of ALUP on controlling and regulating the non-agricultural land growth in China. The study aims to solve two questions (1) whether the implementation of ALUP can effectively control and regulate the construction land growth in China? (2) What's the influence of different implementation intensity of ALUP on the growth of construction land?

\section{Methodology and data}

\subsection{Variables}

One of the important tasks of the ALUP is to reasonably allocate and control newly-added construction land. With this in mind, this paper selects newly-added construction land as the dependent variable. Comprehensively considering the impact of economic and social development, cultivated land protection and intensity of planning control on the expansion of construction land, we select total 6 variables such as population density(pld), GDP per capita $(p g d p)$, industrial structure restructuring $(i d u)$, annual allocation quota of cultivated land converted to construction land $(q a c)$, the proportion of cultivated land protection $(r a p)$ and the intensity of construction land growth management $(I G M)$ as independent variables. Each independent variable is described below, as shown in Table 1.

With the fast growth of economic development and industrialization, the scale of construction land has been substantially enlarged in China (Liu et al., 2014). Socioeconomic factors play dominant role in driving the land use change. Specifically, most important factors such as population growth, economic development, and industrial development are the major forces that contribute to the construction land growth (Deng et al., 2008; Yang, 2014). So this paper uses the population density, GDP per capita and industrial structure restructuring as the independent variables, abbreviated as $p l d, p g d p$ and $i d u$ respectively.

Construction land greatly increased mainly by massively occupation of arable land in China. The ratio of arable land converted to construction land has increased from about $60 \%$ during 1980s -2010 to $67.5 \%$ during 2010-2015 (Liu et al., 2014b, Liu et al., 2018a). The growth of construction land mainly comes from the conversion of cultivated land. The conversion of cultivated land is rigorously constrained by GLUP and ALUP. Therefore, the amount of nonagricultural land converted from arable land is largely determined by the quota of cultivated land conversion allocated by central government. The more conversion quota is permitted, the more construction land growth. So this study selects the annual allocation quota of cultivated land converted to construction land as an independent variable, abbreviated as qac. 
China has implemented its strictest cultivated land protection policy. According to the "Land Management Law" and "Classification of Land Use Status GB / T21010-2017", cultivated land refers to the land on which crops are grown, including mature land, newly developed, reclaimed, and reorganized land, and recreational land (including rotation rest, rest Arable land); land that is mainly planted with crops (including vegetables) with scattered fruit trees, mulberry trees or other trees; the reclamation beaches and tidal flats that can guarantee one season of harvesting every year on average. According to Basic Farmland Protection Regulations (Revised in 2019), basic farmland refers to the non-occupied arable land determined based on the demand for agricultural products in a certain period of population and socioeconomic development, and based on the land use planning. The concept of cultivated land cover the concept of basic farmland, as basic farmland is only a part of the arable land, and it is mainly the high-yield and high-quality part of the arable land. Therefore, not all arable land is basic farmland. Generally speaking, only those arable land classified in the basic farmland protection area are considered basic farmland. Since 2006, China has implemented its "red line 1.8 billion mu" of cultivated land protection and further emphasized this policy in The Outline of National General Land Use Plan in China (20062020), ensuring that the cultivated land should exceed 1.82 and 1.81 billion mu in 2010 and in 2020 respectively. The state regulates that basic farmland must account for more than $80 \%$ of the cultivated land in the administrative area. Basic farmland, especially permanent basic farmland is strictly restricted to be occupied by construction (Chen et al., 2017). The central government also allocates the goal of arable land protection to local government and evaluate their performance accordingly. This strictest arable land protection policy constrains the construction use occupation on arable land (Wang et al., 2010; Chien, 2015). Limited by the data of the rate of basic farmland protection, this paper uses the proportion of cultivated land protection (Abbreviated as rap) as an independent variable to measure the influence of arable land protection policy on the construction land growth. It supposes that there is a negative correlation between the dependent variable and the ratio of cultivated land protection. The more stricter cultivated land protection policy is, the less arable land can be converted to nonagricultural land.

In addition, this study selects the intensity of construction land growth management (IGM) as a policy variable to express the implementation intensity of ALUP. The ALUP is

implemented through the system of land use conversion permission, and the relation between the annual quotas and approval areas can reflect the implementation intensity of ALUP. When the area of approval is larger/higher than the area of annual quota, it suggests that the implementation intensity of ALUP is relaxed; otherwise, it is strict. In view of data availability and continuity, this study discloses the relationship between approval of farmland conversion to non-agricultural land (AFC) and annual quota of farmland conversion to construction use (AQFC) to represent the IGM. The variables are shown in Table 1. This paper supposes that there is a negative correlation between the intensity of construction land growth management and the dependent variable. With growth control management becoming stricter, the growth of newly-added construction land becomes slower.

\subsection{Model}

According to the above analyses, this study will establish the following model and estimate the impact of the implementation of annual land plan on the growth of non-agricultural land at the province-level in China.

$Y_{i t}=C+\delta I G M_{i t}+\beta X_{i t}+\varepsilon_{i t}$ 
Where, $Y_{i t}$ means the quantity of newly-added construction land for the province $i$ in the $t$ year. $I G M_{i t}$ includes the indicators reflecting construction land growth management policy. The variable $X_{i t}$ represents other factors influencing the construction land growth. $\delta$ and $\beta$ are the coefficients for IGMit and $X_{i t}$, respectively. $C$ is the constant, and $\varepsilon$ it is the residual error.

According to the above analysis on the basic model and variables as in Table 1, this study establishes the primary model to evaluate the specific impact of the implementation of annual land plan on the construction land growth by using the panel data of 31 provinces during 2006-2013.

$$
Y_{i t}=c+\delta I G M_{i t}+\alpha_{1} p l d_{i t}+\alpha_{2} p g d p_{i t}+\alpha_{3} i d u_{i t}+\alpha_{4} q a c_{i t}+\alpha_{5} r a p_{i t}+\varepsilon_{i t}
$$

Wherein, $Y_{\text {it }}$ represents the area of newly-increased construction land in every year, $i$ and $t$ are the provinces and years respectively. $p l d_{i t}$ is population density each year, $p g d p_{i t}$ is GDP per capita, $i d u_{i t}$ represents upgrading of industrial structure and it is determined by proportion of secondary and tertiary industries in GDP (Liu et al., 2018b). qac it is the allocation quota of cultivated land converted to non-agricultural use of the ALUP. rapit is the ratio of arable land protection, using the scale of arable land at the end of each year and the scale of arable land at the beginning in 2005 as the rate of arable land protection. $I G M_{i t}$ is the implementation intensity of annual land use plan. $\alpha 1, \alpha 2, \alpha 3, \alpha 4$ and $\alpha 5$ are the coefficient for $p l d, p g d p, i d u, q a c$ and $a p r$ respectively. Other parameters are the same as the formula (1).

\subsection{The impact of annual land use plan}

\subsubsection{The control effect of ALUP}

The effectiveness of ALUP on controlling construction land growth could be judged by the coefficient of the variable $I G M$. If the expected sign is in consistent with the estimated coefficient of $I G M$ and the value significance is statistically on a 5\% level, it means that the ALUP implementation is effective in containing construction land growth. Otherwise, it is not.

\subsubsection{The impact of ALUP}

There are differences in the implementation intensity of ALUP which have different effects on construction land growth. When the ALUP is strictly implemented and the construction land will be curbed, which can be defined as positive effect (PE). On the other hand, if the ALUP is loosely implemented, it means that construction land will increase as a consequence, which can be defined as negative effect (NE).

$$
\left\{\begin{array}{l}
P E=\delta * I G M 0<\frac{A F C}{A Q C L}<1 \\
N E=\delta * I G M \frac{A F C}{A Q C L}>1
\end{array}\right.
$$

Wherein, $P E$ represents the lessened increment of construction land with the strict implementation of ALUP. $N E$ represents the additional increment of construction land due to the relaxed implementation of ALUP. 


\subsection{Study area and data}

Mainland China data of 31 provinces, municipalities and autonomous regions from 2006 to 2013 are included. Due to the data unavailability, Hongkong, Macau and Taiwan are excluded. The data mainly cover socioeconomic and land use change which are obtained from the statistic bureaus of government. Specifically, the socioeconomic data come from China Statistical Yearbook from 2007 to 2014 (NBSC, 2007-2014). Among them the economic data GDP per capita is transformed as constant prices in 2006 (Fig. 1). The data on approval of farmland converted to non-agricultural land were collected from China Land and Resources Year book for the period of 2007-2014 (MLR (Ministry of Land and Resources), 2014). The data on annual quota of farmland converted to nonagricultural use, the ratio of arable land protection, the allocation quota of cultivated land converted to non-agricultural land and newly-increased construction land were collected from Administrative Authority on Land and Resources (MLR (Ministry of Land and Resources), 2013b). It should be noted that China implemented its first national land survey in 1996 and conducted subsequent land surveys from 2007 to 2009. The data of land use were interrupted since the 2nd land survey was conducted, which resulted in a gap during 20092013 compared to previous years. Because of the two land surveys varied in coordinate system, land survey scale, land use classification criteria and the way of area calculation, the gap is finally present in the land use classification results and their land area, for example, the total construction land increased dramatically in 2009 compared to previous year. To solve this inconsistency, the data of total area of cultivated land from 2009 to 2013 should be handled as the initial value of previous year plus variable quantity of the year to represent the final data of year, for example, the 2009 data can be computed using the 2008 value plus the land change in 2008 (Xu et al., 2015). Because of the limitation in data accessibility and consistency, combined with being at the midterm period of The Outline of National General Land Use Plan in China (2006-2020) (SCC (State Council of China), 2008), this paper selects the data from 2006 to 2013 as its study period. The statistical description of the data is shown in Table 2. On the basis of panel data of 31 provinces, regression methods was explored to analyze the relationship between variables and further analyze the multicollinearity between variables. The results in Table 2 show that the Variance Inflation Factor (VIF) values of variables less than 10, indicating that there is no multicollinearity between variables.

To understand significant correlation between dependent and independent variables across the sample size, this paper uses linear regression tests and generates more visual graphs to foresee the significant relationships within binary and ordinary variables into the dataset (Fig. 2). Among of the dependent and independent variables, the $\mathrm{p}$ value of pld, pgdp, rap, IGM, idu and qac with y is $0.25,0.06,0.00,0.01,0.43,0.00$ respectively. Except that the p values of pld and $i d u$ are not significant at the $10 \%$ level, the $p g d p$ variable is significant at the $10 \%$ level, and the other variables are all significant at the 5\% level. Overall, there is a significant linear relationship between $y$ and most independent variables.

Based on the above analysis, we performed further homoscedasticity tests on the regression analysis data. By drawing a scatter plot of residuals and fitted values, it can be roughly seen from Fig. 3 that when $y$ '(the fitted value of $y$ ) is small, the variance of the disturbance term is large. Further examination of the scatter plot of residuals and $p g d p$ of the residuals and explanatory variables $p g d p$ (Fig. 4) shows that the approximate outlines of the two graphs are basically the same, indicating that there may be heteroscedasticity, that is, the variance of the disturbance term varies with the observed value. To further verify whether the data has homoscedasticity, white tests are used to perform homoscedasticity analysis. The result 
shows that $\mathrm{p}=0.000<0.05$, so the original hypothesis is strongly rejected, and heteroscedasticity is considered to exist. This test result confirms the approximate judgment made based on the residual plot.

After the test, the data shows no homoscedasticity but with heteroscedasticity instead.

Because of the heteroscedasticity of the data, it is need to process the heteroscedasticity in the regression analysis. The methods for processing heteroscedasticity include OLS + Robust, Generalized Least Squares (GLS), Weighted Least Squares (WLS), and feasible generalization least squares (abbreviated FGLS). This paper uses panel data to analyze the econometric model. When dealing with panel data regression analysis, we mainly consider the heteroscedasticity problem of the fixed effects model and the OLS model. Because the random effects model uses FGLS estimation, the heteroscedasticity is already controlled by itself (Davidson and MacKinnon, 2004; Baltagi, 2005; Chen, 2014).

\section{Results}

\subsection{Estimation results}

This study uses econometric model to evaluate the impact of the implementation of ALUP respectively. The OLS model, fixed effects (FE) model and random effects (RE) model were employed to examine the Eq. (2) coefficients using software STATA 14.0. After F test, it was determined that RE model and FE model work better than OLS model. Further analysis with Hausman's test showed that the RE model was the best choice. Because the optimal model in this paper is a random effect model RE using FGLS estimation, the problem of data heteroscedasticity is eliminated (Davidson and MacKinnon, 2004; Baltagi, 2005; Chen, 2014). Therefore this study used the RE model to analyze the data. The model test are significant $\left(\mathrm{R}^{2}=0.55\right.$, and $\left.\mathrm{p}=0.000\right)$, therefore it can be used for further analysis. The results of estimate are shown in Table 3.

The results show that the estimated coefficients for IGM is negative and its signs is in line with anticipations in Table 1, signifying that the ALUP implementation can effectively restrict construction land growth. The signs of pld and $i d u$ are negative, however, their coefficients are not significant at the $10 \%$ level, which implicate that the expected effect of population density increase and industrial structure adjustment on urban land use need more evidence. The positive sign of qac suggests that the allocation quota of cultivated land conversion have a positive influence on construction land growth. Namely, the more quota of cultivated land conversion permitted, the more non-agricultural use will be promoted. The sign of rap is positive and its inconsistency with the expection, indicating that the ratio of arable land protection increasing are not effective to constrain non-agricultural land growth. The reason for this result may be related to that those developed regions that are lack of cultivated land conversion quota can get supplementary cultivated land indicators through trading land development rights with those developing regions that have abundant cultivated land within the same province (Wang et al., 2010; Chien, 2015). This method of acquiring development land quota loosens the control of the construction land growth to some extent.

\subsection{The effectiveness of ALUP}

The estimated coefficient for the variable of IGM is negative and also expressed significantly at the 5\% level, thus it is consistent with the expected sign. It indicates that the ALUP implementation was effective in curbing the construction land growth. The results indicate 
that the increased non-agricultural land reduced by about 1721 ha with a $1 \%$ increment of the intensity of growth management. These results are in consistent with other studies which show that the land use policies and regulations implementation can control non-agricultural land growth in China (Wang et al., 2018).

\subsection{Influence of the implementation intensity of annual land use plan}

The formula (3) was used to analyze the impact of the implementation intensity of ALUP on construction land growth and the results are shown as follows. Due to the differences in the implementation intensity of ALUP, the implementation has different effects on the growth of construction land. According to formula (3), the positive and negative effects of the implementation intensity of ALUP are calculated. When ALUP is strictly implemented, it can effectively control the increase in the area of construction land. When ALUP is loosely implemented, it means that construction land will increase accordingly. According to the calculation results, in general, during the year of 2006-2013, the construction land growth has much to do with the implementation intensity of ALUP, which decreases 30,892 ha under strict implementation while increases an extra 181,451 ha with relaxed implementation.

The impact of the implementation intensity of ALUP on construction land growth shows significant spatial difference. The Fig. 5 shows that the positive effect of the strict implementation of ALUP in regions are distributed in north-east, east and north-west China, specifically, those regions mainly include Qinghai, Gansu, Ningxia, Tibet, Beijing, Shanghai, Guangdong, Jilin and Heilongjiang; Among of them, Beijing and Shanghai have the best control effects. While the provinces in central and southwestern China have weaker implementation effect than above regions. Because of the constraints of potential available land, Beijing and Shanghai take strict measures to manage the land use and emphasis the intensive utilization of land resources, and they have smaller construction land expansion of about 5191 ha and 6070 ha average increase in 2006-2013 respectively below the national an average increase of 17,583 ha in the same period. In the western region of Qinghai, Ningxia Gansu, and Tibet, their better control effect may closely relate to the relatively slow level of economic development, thus the land quota allocated can satisfy the socio-economic development demand for the construction and seldom be broken. The actual average increment of construction land in those province is about 6229 ha, $6872 \mathrm{ha}, 11,279$ ha and 1437 ha below the national average scale of land growth during the study period.

Heilongjiang and Jilin are faced with the slowdown in the overall economy, which are associated with weaker demand for construction land. Thus, those provinces have the positive effect of the implementation of annual land use plan.

The Fig. 6 shows that the negative effect of the relaxed implementation of ALUP in regions is mostly concentrated on southwest and central zones, and southeast coastal of China.

Specifically, those regions mainly loacated in Yunnan, Guizhong, Sichuan, Hunan, Hubei and Inner Mongolia. In north-west, north-east and east coast China, the amount of extra increased construction land was smaller than those provinces in south-west and central zones. During our selected period, the amount of extra increased construction land in western and central zones are 2.80 times and 1.35 times than that in the eastern region respectively. The western and central regions attract a lot of investment and further accelerate construction land expansion under the policy support of the West Development Strategy and Rising of the Central Regions. From 2006to 2013, the actual newly-construction land has increased about 23,436 ha and 25,235 ha in Sichuan and Inner Mongolia respectively. For the central provinces of Hunan, Hubei, Henan, Anhui provinces, the average area of newly-construction land are between 20,098 ha and 27,356 ha, which are higher than the national average growth 
of 17,583 ha in study period. Economy level of eastern provinces such as Zhejiang and Fujian grow fast, which induce more demand on constructive land and their actual newly-increased construction land were up to 254,550 ha and 164,868 ha during 2006-2013. So in those provinces, the local governments usually breaking through the quota of development land allocated by ALUP when the allocation quota can't meet the need of land demand for economic development. It is difficult to effectively restrict the non-agricultural land growth and cause the extra increased.

\section{Discussion}

\subsection{The implementation of ALUP can control and regulate the construction land growth}

From the estimation results in Table 3 ,the incremental area of construction land reduced by about 1721 ha with a $1 \%$ increment of the intensity of growth management, which indicate that the ALUP can regulate and control the construction land growth to some extent. ALUP plays an important role in guaranteeing successful regulate and constrain construction land growth. Ever since 1987, China has started to implement the annual land use plan policy. A more formal practice was brought about in 1998 in the revised Land Management Law and then "Measures for the Administration of Annual Land Use Plan" was published in 1999 to ensure the effective implementation of the ALUP (Ding, 2003). There are three main quotas being stipulated by the ALUP at each administrative level from the national to county level, including the maximum total scale of non-agricultural land, arable land converted to construction use and the minimum total scale of cultivated land to be maintained (Tan et al., 2011).Those quotas allocated by higher-level authority are grounded in the economic and social development program, national industrial policies and the general land use planning. Each quota being executed by a lower-level authority should be consistent with the quota allocated by the higher-level authority. The core task of ALUP is to protect farmland amount, therefore the area of newly-increased construction land in the year is strictly controlled and implemented through the system of land use conversion permission. In 2003, the central government applied the land policy as one of the main tools in national macro-control regulations (Tian and Ma, 2009), which mainly includes the regulation of land supply scales, land supply way, land supply policy, land price and land revenue. The annual land use plan, as an important tool in accomplishing the goals of macro-control, aims to extend from arable land protection to double targets, including controlling farmland conversion and macrocontrol simultaneously. The land use plan plays an increasingly prominent role in land management and has an irreplaceable position in the land control system. In order to better implement the ALUP and strictly restrain the non-agricultural land growth, the central government has revised "Measures for the Administration of Annual Land Use Plan" in 2004, 2006 and 2016. In addition, the central government stepped up its supervision and administration by taking advantage of satellite remote-sensing technology since 2000 and implemented land supervision system since 2007 to monitor the area of newly-increased construction land and cultivated land conversion breakthrough the allocation quota of annual land use plan (Zhong et al., 2014b; Lv et al., 2012). The above policies jointly play a role in promoting the efficiency of annual land use plan implementation.

\subsection{Impact of national development strategy and region's land policy}


The analysis result suggests that the implementation effects of ALUP showed significant spatial difference with the implementation effects in most eastern regions and northeast are better than western and central zones. Specially, the implementation intensity of ALUP varies in different provinces in the study period. Compared the scale of actual newly-added construction land with that allocation quota in ALUP, Inner Mongolia's actual newly-added construction land is twice the allocation quota in annual land use plan, Xinjiang is 2.82 times; Hunan, Anhui, Guizhou, Sichuan and Hubei are 1.90, 1.87, 1.82, 1.79, 1.77 times respectively. The actual newly-added construction land of these provinces are larger than the allocation quota that annual land use plan expected. However, in Jilin, Heilongjiang in the northeast, this ratio is 0.98 and 1.15 respectively, and in the east of Tianjin, Shanghai and Tibet, this ratio is 1.04, 1.12 and 1.01 respectively. The actual newly-added construction land of these provinces are basically in consistent with the annual land use plan that issued (Fig. 7). National development strategy and region's different land policy may contribute to this result. China has implemented several national development strategies to balance the development discrepancy among regions since 2000, which mainly includes West Development Strategy, Rising of The Central Regions and Revitalization of The Northeast Old Industrial Base Plan. These policies have attracted a large amount of investment and promoted economic development, thereby promoting the growth of construction land in inland regions, especially in the central and western regions (Kuang et al., 2016). As can be seen from Fig. 8 in the 31 provinces, the average annual growth rate of construction land among the provinces shows that most provinces in the west and some provinces along the coast have experienced rapid growth. The average annual construction land in Xinjiang, Guizhou, and Ningxia in the western region have growth rates of $2.43 \%, 2.57 \%$, and $3.10 \%$ respectively. The average annual growth rates of construction land in Chongqing and Yunnan were also at a relatively high level, reaching $1.94 \%$ and $1.97 \%$, which were higher than the national average annual growth rate of $1.55 \%$. The average annual growth rate of construction land in Zhejiang and Fujian is much faster than in other provinces. The growth of construction land in Northeast China is relatively small. The average annual growth rates of Heilongjiang, Jilin and Liaoning are only $0.75 \%, 0.88 \%$ and $1.45 \%$. In general, during the study period, the growth rate of construction land in the western region was up to $14.35 \%$, which was faster than that in the central and eastern regions. In addition, the central government implemented different land policies in different regions, which shows a moderate inclination to allocate more newly-added construction land quotas in the western regions ${ }^{1}$. At the same time, the government strictly controls the land quota in eastern zones and pays more attention to improving land use efficiency (Chen et al., 2016). To some extent, those policies affected the non-agricultural land growth and resulted in the spatial differences in the implementation of ALUP.

\subsection{Effective with partial success in ALUP implementation}

The evaluated results from Table 3 indicate that the implementation of ALUP has a positive impact on constraining non-agricultural land growth, namely, the ALUP and its implementation did decrease the increment of construction land in China. Although the implementation of ALUP is effective, it is difficult to completely prevent the trend of rapid construction land growth. According national land surveys from year 2006 to 2013, the actual rate of construction land growth was much faster and reached $12.43 \%$ while the expected rate was $7.65 \%$ in The Outline of National General Land Use Plan in China (20062020) (SCC (State Council of China), 2008). Further analysis of the relationship between the average annual actual increase in construction land and the scale of newly-added construction land allocated in the annual land use plan was focused on 2007-2013, due to the lack of data 
on new construction land quotas in the 2006 annual land use plan. It can be seen from Fig. 9 that the actual new construction land in Tianjin, Shanghai, Jilin, Heilongjiang, Tibet and other provinces is basically the same as the quota for new construction land in the annual land use plan. The scale of additional construction land is much higher than the new construction land quota in the annual land use plan. Among them, Xinjiang, Jiangsu, Zhejiang, Shandong, Inner Mongolia, Henan, Sichuan, and Hubei provinces have an average annual actual new construction land scale that is larger than land use. The quotas in the annual plan are 21,607 ha, 15,217 ha, 14,998 ha, 14,883 ha, 13,541ha, 13,508 ha and 10,645 ha and 10,062 ha, and the remaining provinces are all below 10,000 ha. It shows that among the 31 provinces in the country, about $84 \%$ of the province' s actual increase in construction land has far exceeded the expected land use annual plan, and only about $16 \%$ of the provinces meet the planning expectations. Thus it can be described as effective though not completely successful when we take both the goal achievement and effectiveness into consideration. Several reasons account for this result. First, the goals of land administration is inconsistent between the central and local governments. The central government must keep a whole dynamic balance between economic growth and food security. However, the local governments put more emphasis on economic growth and land finance revenue than on food security (Lichtenberg and Ding, 2008; Qian, 2013). They are tempted to evade the approval formalities and provide more lands by breaking through the annual land quotas assignment to stimulate local economic development (Deng, 2005; Xu et al., 2009). To solve this problem and restrain the local government's impulse, the central government has to do more to strengthen construction land growth management. Second, a contradiction existed between the management mode of annual land use plan and market economy development. On one hand, ALUP involved in land use in various regions and departments which require the ALUP formation must be based on sufficient information. However, under the circumstances of quick market economy development in China, it is difficult to acquire the information of previous year exactly. This information asymmetry makes it difficult for the upper government to satisfy the actual demands of local government accordingly. On the other hand, the annual land quota is mandatorily allocated with little elasticity. At present, with China's fast economic development, local demand for lands is too large to be met by the rigid constraints, especially in areas of rapid industrialization and urbanization. This conflict pushes the local governments to violate the designated allocation to seek more land for development. Third, another reason may lie in the system for evaluating the performances of cadres in local government, which is mainly based on the GDP and fiscal income (Blanchard and Shleifer, 2001; Li, 2014). As a result, the regulations of the central government would be ignored by the local government which will supply more land beyond the ALUP restrictions to achieve higher economic growth. All three reasons mentioned above work together to explain the effective but yet not successful regulation of construction land control.

\subsection{Improving policy implementation of annual land use plan}

Based on above analysis, this study proposes some suggestions to improve the policy implementation in the future. First, coordination between central and local government should be strengthened. The local governments should shift their main pursuit of economic development, which relies too much on land finance to seek a balance between the cultivated land protection and economic development. On the basis of ensuring the demand for economic development land, the local government strictly implements the policy of balancing cultivated land occupation and compensation. For provinces that have difficulty in achieving the balance of cultivated land occupation and compensation, according to the "Regulations for the Overall Management of Supplementary Cultivated Land by the Provinces" issued by 
the General Office of the State Council, they can apply state-wide co-ordination and supplementation to achieve a cross-province balance of cultivated land occupation and compensation in order to seek the relationship between economic development land and farmland protection. Second, some flexible market measures should be introduced to reform the mandatory management plan. The essence of ALUP is the allocation of land development rights, therefore local government can obtain extra development rights beyond the plan through "increasing vs. decreasing balance of urban-rural built land". Third, the government should make more accurate predictions of the social economic development situation and land needs so that they can allocate the quotas more reasonable. Besides consideration of the national economic and social development, industrial policy, regional development potential and dynamic change of population should also be taken into account at the same time. Population development and economic layout should be compatible with the carrying capacity of resources and environment. Therefore, on the basis of the evaluation of resource and environment carrying capacity and the suitability of land space, the construction land scale should be rationally allocated and spatially optimized according to the regional resource and environmental carrying capacity. Fourth, the evaluating system for the local government officials should be reformed. Environmental protection, including arable land protection and land intensive use should be considered in the evaluating system (Yang, 2014; Yang et al., 2015). In addition, the central government should strengthen the supervision of land use and management in the local government. For example, establishing the dynamic monitoring system through remote sensing technology, denouncing, condemning and punishing the illegal activity in land abuse. Finally, on March 12, 2020, China has released "The Decision of the State Council on the right to approve and authorize land use". It mainly involves the decentralization of approval authority in two aspects: first, the transfer of the authorized right of agricultural land other than permanent basic farmland from the State Council to governments of provinces, autonomous regions and municipalities for approval; second, the transfer of the authorized right of the permanent basic farmland from State Council to the people's governments of some provinces, autonomous regions, and municipalities for approval. The decentralization of relevant approval rights is aimed at "increasing efficiency", giving provincial-level local governments more autonomy to solve the problem of "difficult landing" and "slow landing" of project land, thereby improving the efficiency of approval, project landing efficiency and land use efficiency. Although the approval process "decentralized", it does not "relaxed". Therefore, this may have a certain impact on the implementation intensity of the annual land use plan, which may be different in different provinces, but it will not threaten the implementation effect of the annual land use plan. In the future, local governments should strictly follow the constraints of territory spatial planning, land supply plans and space use control, and strictly implement the annual land use plan to ensure better implementation of the annual land use plan.

\section{Conclusions}

The empirical results show that the ALUP implementation can restrain the non-agricultural land growth. Results of model estimation suggest that the increased area of construction land has reduced about 1721 ha with a $1 \%$ increment of the intensity of construction land growth. During the study period, construction land growth is closely related to the implementation intensity in which it has decreases 30,892 ha under strict implementation while increases an extra 181,451 ha with relaxed implementation.The implementation effect of ALUP on construction land growth shows significant spatial difference. The effectiveness suggests that the regions of northwestern and eastern China is better than the southwest and central regions. National development strategy and region's differentiation land policy may have 
contributed to this phenomenon.The implementation of the ALUP is effective despite being, to some extent, not fully successful. The ALUP can decrease the conversion of construction land from arable land, but it is difficult to fundamentally prevent its rapid expansion trend in China. The land administration conflict between central and local governments, together with the imperfect ALUP management and the system for evaluating local government performance, may contribute to this result.

Similar as many studies, there are some limitations of this research. First, construction land is not only affected by economic and social factors. In fact, other factors such as natural, location conditions and policy factors also contribute to the situation ( $\mathrm{Li}$ et al., 2015; Xu et al., 2011; Ye et al., 2013). However, because of the limitation in data availability and continuity, it is hard to include more detailed variables when the research object includes 31 provinces. That's why the economic and social factors such as population growth, economic development and industrial structure were adopted in this analysis while ignoring other natural and location factors. The study can be enhanced by applying more indicators if these variables are available in further research so that we can get a better understanding of the construction land growth details. Second,there is a certain gap / difference in the economic volume of municipalities and provinces, and there is some uncertainty about the results of our panel model operation. However, considering the administrative level of China, the municipalities are on the same level with the provinces, and this article does a global analysis of 31 provinces in mainland China. Therefore, the four municipalities in Beijing, Shanghai, Tianjin, and Chongqing cannot be omitted, which are also included in other studies. (Chen et al., 2015; Lai et al., 2016). Third, although National Land Census has the advantage in the collecting land use data with more reliability and continuity, the remote sensing technology is widely applied for the detailed spatially explicit information and relative objectivity (Pandey and Seto, 2015). Till now, China has carried out two land surveys in 1984-1996 and 20072009 respectively. The land use classification was different between the two surveys, which resulted in a gap during 2009-2013 compared to previous years. In order to be more objective and avoid the error of technology in statistical data, future research should not only rely on land survey, but also on the application of remote sensing data.

\section{Acknowledgments}

This work was supported by the Humanities and Social Sciences Fund of the Ministry of Education of China (Grant Numbers. 20YJCZH250), Major Program of National Fund of Philosophy and Social Science of China (Grant Numbers. 17ZDA061), National Natural Science Foundation of China (Grant

Numbers. 41571162,41501185,41771189,41701196),Science Foundation of Education Department of Yunnan Province (Grant Numbers. 2019J0073).

\section{References}

Alexander, E.R., 2001. A Transaction-cost Theory of Land Use Planning and Development Control: Towards the Institutional Analysis of Public planning. THe Town Planning Review. pp. $45-75$.

Ali, A.K., 2008. Greenbelts to contain urban growth in Ontario, Canada: promises and prospects. Plan. Pract. Res. 23 (4), 533-548. 
Alnsour, J.A., 2016. Managing urban growth in the city of Amman. Jordan. Cities 50, 93-99. Amati, M., 2016. Green belts: a twentieth-century planning experiment. Urban Green Belts in the Twenty-first Century. Routledge, pp. 21-38.

Anas, A., Rhee, H.J., 2006. Curbing excess sprawl with congestion tolls and urban boundaries. Reg. Sci. Urban Econ. 36 (4), 510-541.

Angel, S., Parent, J., Civco, D.L., Blei, A., Potere, D., 2011. The dimensions of global urban expansion: estimates and projections for all countries, 2000-2050. Prog. Plann. 75, 53-107.

Baltagi, B.H., 2005. Econometric Analysis of Panel Data 3rd Edition. Chichester, West Sussex. John Wiley\& Sons Ltd., England.

Bengston, D.N., Youn, Y.C., 2006. Urban containment policies and the protection of natural areas: the case of Seoul's Greenbelt. Ecol. Soc. 11 (1), 3.

Bengston, D.N., Fletcher, J.O., Nelson, K.C., 2004. Public policies for managing urban growth and protecting open space: policy instruments and lessons learned in the United States. Landsc. Urban Plan. 69 (2), 271-286.

Blanchard, O., Shleifer, A., 2001. Federalism with and without political centralization: china versus Russia. Imf Staff. Pap. 48 (1), 171-179.

Bradshaw, T.K., Muller, B., 1998. Impacts of rapid urban growth on farmland conversion: application of new regional land use policy models and geographical information Systems1. Rural Sociol. 63 (1), 1-25.

Bramley, G., 1993. The impact of land use planning and tax subsidies on the supply and price of housing in Britain. Urban Stud. 30 (1), 5-30.

Burchell, R.W., Mukherji, S., 2003. Conventional development versus managed growth: the costs of sprawl. Am. J. Public Health 93 (9), 1534-1540.

Chen, Q., 2014. Advanced Econometrics and Stata Applications (Second Edition). Higher Education Press, Beijing.

Chen, Z., Wang, Q., Chen, Y., Huang, X., 2015. Is illegal farmland conversion ineffective in China? Study on the impact of illegal farmland conversion on economic growth. Habitat Int. 49, 294-302.

Chen, Y., Chen, Z., Xu, G., Tian, Z., 2016. Built-up land efficiency in urban China: insights from the general land use plan (2006-2020). Habitat Int. 51, 31-38.

Chen, Q., Jiang, P., Cai, L., Shan, J., Zhang, Y., Wang, L., Li, M., Li, F., Zhu, A., Chen, D., 2017. Delineation of a permanent basic farmland protection area around a city centre: case study of Changzhou City, China. Land Use Policy 60, 73-89.

Cheng, H., Shaw, D., 2018. Polycentric development practice in master planning: the case of China. Int. Plan. Stud. 23 (2), 163-179.

Chien, S.-S., 2015. Local farmland loss and preservation in China-a perspective of quota territorialization. Land Use Policy 49, 65-74.

Couch, C., Karecha, J., 2006. Controlling urban sprawl: some experiences from Liverpool. Cities 23 (5), 353-363.

Davidson, R., MacKinnon, J.G., 2004. . Econometric Theory and Methods Vol. 5 Oxford University Press, New York. 
Dempsey, J.A., Plantinga, A.J., Kline, J.D., Lawler, J.J., Martinuzzi, S., Radeloff, V.C., Bigelow, D.P., 2017. Effects of local land-use planning on development and disturbance in riparian areas. Land Use Policy 60, 16-25.

Deng, F.F., 2005. Public land leasing and the changing roles of local government in urban china. Ann. Reg. Sci. 39 (2), 353-373.

Deng, X., Huang, J., Rozelle, S., Uchida, E., 2008. Growth, population and industrialization, and urban land expansion of China. J. Urban Econ. 63 (1), 96-115.

Ding, C., 2003. Land policy reform in China: assessment and prospects. Land Use Policy 20 (2), 109-120.

Du, Y., Xie, Z., Zeng, Y., Shi, Y., Wu, J., 2007. Impact of urban expansion on regional temperature change in the Yangtze River Delta. J. Geogr. Sci. 17, 387-398.

Esparza, A.X., Carruthers, J.I., 2000. Land use planning and exurbanization in the rural mountain west evidence from Arizona. J. Plan. Educ. Res. 20 (1), 23-36.

Ewing, R.H., 2008. Characteristics, causes, and effects of sprawl: a literature review. Urban Ecol. 519-535.

Farthing, S.M., 2001. Local land use plans and the implementation of new urban development. Eur. Plan. Stud. 9 (2), 223-242.

Foley, J.A., DeFries, R., Asner, G.P., Barford, C., Bonan, G., Carpenter, S.R., et al., 2005. Global consequences of land use. Science 309 (570), - 574.

Freilich, R.H., Peshoff, B.G., 1997. The social costs of sprawl. Urban Lawyer 183-198. Gennaio, M.-P., Hersperger, A.M., Bürgi, M., 2009. Containing urban sprawl—evaluating effectiveness of urban growth boundaries set by the Swiss Land Use Plan. Land Use Policy 26 (2), 224-232.

Godschalk, D.R., 2004. Land use planning challenges: coping with conflicts in visions of sustainable development and livable communities. J. Am. Plan. Assoc. 70 (1), 5-13.

Grant, J., 2009. Theory and practice in planning the suburbs: challenges to implementing new urbanism, smart growth, and sustainability principles. Plan. Theory Pract. 10 (1), 11-33.

Halleux, J.-M., Marcinczak, S., van der Krabben, E., 2012. The adaptive efficiency of land use planning measured by the control of urban sprawl. The cases of the Netherlands, Belgium and Poland. Land Use Policy 29 (4), 887-898.

Johnson, M.P., 2001. Environmental impacts of urban sprawl: a survey of the literature and proposed research agenda. Environ. Plan. A 33, 717-735.

Jurjevich, J.R., Chun, N., Rancik, K., Proehl, R., Michel, J., Harada, M., Morris, R., 2017. Coordinated Population Forecast for Columbia county, Its Urban Growth Boundaries (UGB), and Area Outside UGBs 2017-2067.

Kim, K.-H., Pauleit, S., 2007. Landscape character, biodiversity and land use planning: the case of Kwangju City Region, South Korea. Land Use Policy 24 (1), 264-274.

Kuang, W., Liu, J., Dong, J., Chi, W., Zhang, C., 2016. The rapid and massive urban and industrial land expansions in China between 1990 and 2010: a CLUD-based analysis of their trajectories, patterns, and drivers. Landsc. Urban Plan. 145, 21-33.

Lai, L., Huang, X., Yang, H., Chuai, X., Zhang, M., Zhong, T., et al., 2016. Carbon emissions from land-use change and management in China between 1990 and 2010. Sci. Adv. 2 (11), e1601063. 
Li, J., 2014. Land sale venue and economic growth path: evidence from China's urban land market. Habitat Int. 41, 307-313.

Li, H., Wei, Y.D., Liao, F.H., Huang, Z., 2015. Administrative hierarchy and urban land expansion in transitional China. Appl. Geogr. 56, 177-186.

Lichtenberg, E., Ding, C., 2008. Assessing farmland protection policy in China. Land Use Policy 25 (1), 59-68.

Liu, Y., Huang, X., Yang, H., Zhong, T., 2014a. Environmental effects of land-use/cover change caused by urbanization and policies in Southwest China Karst area - a case study of Guiyang. Habitat Int. 44, 339-348.

Liu, J., Kuang, W., Zhang, Z., Xu, X., Qin, Y., Ning, J., et al., 2014b. Spatiotemporal characteristics, patterns, and causes of land-use changes in China since the late 1980s. J. Geogr. Sci. 24 (2), 195-210.

Liu, J., Ning, J., Kuang, W., Xu, X., Zhang, S., Yan, C., et al., 2018a. Spatio-temporal patterns and characteristics of land-use change in China during 2010-2015. Acta Geographica Sinica 73 (5), 789-802.

Liu, Y., Yu, H., Liu, D., Zhu, L., 2018b. Spatial differentiation mechanisms of the pattern evolution of construction land development intensity in Northeast China. Acta Geographica Sinica 73 (5), 818-831.

Lu, D., Mao, W., Yang, D., Zhao, J., Xu, J., 2018. Effects of land use and landscape pattern on PM2. 5 in Yangtze River Delta, China. Atmospheric Pollution Research 9 (4), 705-713.

Lu, D., Xu, J., Yue, W., Mao, W., Yang, D., Wang, J., 2020. Response of PM2. 5 pollution to land use in China. J. Clean. Prod. 244, 118741.

Lv, X., Zhong, T.Y., Zhang, X.L., Huang, X.J., Tian, X., 2012. Effects of land supervision on containing the illegal land use in China. China Popul. Resour. Environ. 22 (8), 121-127.

Lv, X., Huang, X.J., Zhong, T.Y., Zhang, Q., J, 2015. The controlling effects of land-use planning on construction land expansion based on the perspective compositing consistency and effectiveness. Journal of natural resources 30 (2), 176-187.

MLR (Ministry of Land and Resources), 2013a. (2003-2013). China Land and Resources Yearbook. Ministry of Land and Resources of China., Beijing.

MLR (Ministry of Land and Resources), 2013b. (2006-2013). China Land Use Change Survey. Ministry of Land and Resources, Beijing.

MLR (Ministry of Land and Resources), 2014. (2007-2014). China land and resources yearbook. Ministry of Land and Resources of China, Beijng.

Munroe, D.K., Croissant, C., York, A.M., 2005. Land use policy and landscape fragmentation in an urbanizing region: assessing the impact of zoning. Appl. Geogr. 25 (2), 121-141.

NBSC (National Bureau of Statistics of China), 2007-2014. (2007-2014). China Statistical Yearbook. China Statistics Press, Beijing.

Pandey, B., Seto, K.C., 2015. Urbanization and agricultural land loss in India: comparing satellite estimates with census data. J. Environ. Manage. 148, 53-66.

Qian, Z., 2013. Master plan, plan adjustment and urban development reality under China's market transition: a case study of Nanjing. Cities 30, 77-88. 
Rao, P.S., Gavane, A.G., Ankam, S.S., Ansari, M.F., Pandit, V.I., Nema, P., 2004. Performance evaluation of a green belt in a petroleum refinery: a case study. Ecol. Eng. 23 (2), 77-84.

Razin, E., 1998. Policies to control urban sprawl: Planning regulations or changes in the'rules of the game'? Urban Stud. 35 (2), 321-340.

Rydin, Y., 1998. Land use planning and environmental capacity: reassessing the use of regulatory policy tools to achieve sustainable development. J. Environ. Plan. Manag. 41 (6), 749-765.

Saizen, I., Mizuno, K., Kobayashi, S., 2006. Effects of land-use master plans in the metropolitan fringe of Japan. Landsc. Urban Plan. 78 (4), 411-421.

SCC (State Council of China), 2008. Outline of National Overall Land Use Planning in China (2006-2020). Beijing: China Legal Publishing House.

Schetke, S., Haase, D., Kötter, T., 2012. Towards sustainable settlement growth: a new multicriteria assessment for implementing environmental targets into strategic urban planning.

Environ. Impact Assess. Rev. 32 (1), 195-210.

Scolozzi, R., Geneletti, D., 2012. A multi-scale qualitative approach to assess the impact of urbanization on natural habitats and their connectivity. Environ. Impact Assess. Rev. 36, 922.

Seto, K.C., Fragkias, M., Güneralp, B., Reilly, M.K., 2011. A meta-analysis of global urban land expansion. PLoS One 6 (8), e23777.

Sharifi, A., Chiba, Y., Okamoto, K., Yokoyama, S., Murayama, A., 2014. Can master planning control and regulate urban growth in Vientiane, Laos? Landsc.Urban Plan 131, 113.

Tan, R., Qu, F., Heerink, N., Mettepenningen, E., 2011. Rural to urban land conversion in China - How large is the over-conversion and what are its welfare implications? China Econ. Rev. 22 (4), 474-484.

Tian, L., Ma, W., 2009. Government intervention in city development of China: a tool of land supply. Land Use Policy 26 (3), 599-609.

United Nations. World Urbanization Prospects: The 2014 Revision Population Database Available online: http://esa.un.org/unpd/wup/index.htm.

Van der Vlist, M.J., 1998. Land use planning in the Netherlands; finding a balance between rural development and protection of the environment. Landsc. Urban Plan. 41 (2), 135-144.

van Lier, H.N., 1998v. The role of land use planning in sustainable rural systems. Landsc. Urban Plan. 41 (2), 83-91.

Wang, H., Tao, R., Tong, J., 2009. Trading land development rights under a planned land use system: the Zhejiang Model. China World Econ. 17 (1), 66-82.

Wang, H., Tao, R., Wang, L., Su, F., 2010. Farmland preservation and land development rights trading in Zhejiang, China. Habitat Int. 34 (4), 454-463.

Wang, J., Lin, Y., Glendinning, A., Xu, Y., 2018. Land-use changes and land policies evolution in China's urbanization processes. Land Use Policy 75, 375-387.

Weitz, J., Moore, T., 1998. Development inside urban growth boundaries. Oregon's empirical evidence of contiguous urban form. J. Am. Plann. Assoc. 64 (4), 425-440. 
Xu, J., Yeh, A., Wu, F., 2009. Land commodification: new land development and politics in China since the late 1990s. Int. J. Urban Reg. Res. 33 (4), 890-913.

Xu, K., Kong, C., Li, J., Zhang, L., Wu, C., 2011. Suitability evaluation of urban construction land based on geo-environmental factors of Hangzhou. China. Computers \& Geosciences 37 (8), 992-1002.

Xu, G., Huang, X., Zhong, T., Chen, Y., Wu, C., Jin, Y., 2015. Assessment on the effect of city arable land protection under the implementation of China's National General Land Use Plan (2006-2020). Habitat Int. 49, 466-473.

Yang, H., 2014. China must continue the momentum of green law. Nature 509 535-535.

Yang, H., Huang, X., Thompson, J.R., Flower, R.J., 2014. Soil pollution: urban brownfields. Science 344 (6185), 691-692.

Yang, H., Huang, X., Thompson, J.R., Flower, R.J., 2015. Enforcement key to China's environment. Science 347, 834-835.

Yang, H., Huang, X., Thompson, J.R., Bright, R.M., Astrup, R., 2016. The crushing weight of urban waste. Science 351 674-674.

Ye, Y., Zhang, H., Liu, K., Wu, Q., 2013. Research on the influence of site factors on the expansion of construction land in the Pearl River Delta, china: by using GIS and remote sensing. Int. J. Appl. Earth Obs. Geoinf. 21, 366-373.

Zhang, M., Huang, X., Chuai, X., Yang, H., Lai, L., Tan, J., 2015. Impact of land use type conversion on carbon storage in terrestrial ecosystems of China: a spatial-temporal perspective. Sci. Rep. 5, 10233.

Zhong, T.Y., Huang, X.J., Zhang, X.Y., Scott, S., Wang, K., 2012. The eff ;ects of basic arable land protection planning in Fuyang County, Zhejiang Province. China. Applied Geography 35 (1-2), 422-438.

Zhong, T., Mitchell, B., Huang, X., 2014a. Success or failure: evaluating the implementation of China's national general land use plan (1997-2010). Habitat Int. 44, 93-101.

Zhong, T., Huang, X., Ye, L., Scott, S., 2014b. The impacts on illegal farmland conversion of adopting remote sensing technology for land inspection in China. Sustainability 6 (7), 44264451.

Zhou, Y., Huang, X., Chen, Y., Zhong, T., Xu, G., He, J., Xu, Y., Meng, H., 2017. The effect of land use planning (2006-2020) on construction land growth in China. Cities 68, 37-47. 
Table 1 Variable and anticipated signs.

\begin{tabular}{lll}
\hline variable & variable definitions & Anticipated signs \\
\hline$y$ & Newly-added construction land & $/$ \\
$c$ & Constant & $+/-$ \\
$p l d$ & Population density & + \\
$p g d p$ & GDP per capita & $+/-$ \\
$i d u$ & Proportion of secondary and tertiary industries in & + \\
& GDP & - \\
qac & Allocation the annual quota of arable land & - \\
& converted to construction use & \\
IGM & The ratio of arable land protection & IGM $=1-\frac{\mathrm{AFC}}{\mathrm{AQFC}}$ \\
$\varepsilon$ & Residual error & \\
\hline
\end{tabular}


Table 2 Descriptive statistics of variables used in the model.

\begin{tabular}{llllll}
\hline Variable & Number of observations & Minimum & Maximum & Mean & Std. deviation \\
\hline$y$ & 248 & 601.73 & 57496.81 & 17582.70 & 12205.07 \\
pld & 248 & 2.37 & 2889.06 & 396.46 & 502.75 \\
pgdp & 248 & 5514 & 86,776 & 28627.09 & 17208.80 \\
IGM & 248 & -7.44 & 0.77 & 0.72 & 3.10 \\
rap & 248 & 68.49 & 136.63 & 104.12 & 1.13 \\
idu & 248 & 67.28 & 99.4 & 88.52 & 1.12 \\
qac & 248 & 393.33 & 14646.67 & 5727.04 & 2994.55 \\
\hline
\end{tabular}


Table 3 Estimation results.

\begin{tabular}{|c|c|c|c|c|c|c|c|c|c|}
\hline \multirow[t]{2}{*}{ Variable } & \multicolumn{4}{|l|}{ Fixed effect } & \multicolumn{5}{|c|}{ Random effect } \\
\hline & Coef. & Std. Err. & t-Statistic & $P>|t|$ & & Coef. & Std. Err. & t-Statistic & $P>|t|$ \\
\hline pld & 9.5372 & 15.2598 & 0.62 & 0.533 & & -0.0458 & 2.649 & -0.02 & 0.986 \\
\hline$p g d p$ & -0.0308 & 0.0827 & -0.37 & 0.709 & & 0.0312 & 0.0547 & 0.57 & 0.568 \\
\hline$I G M$ & -1317.139 & 783.047 & -1.68 & 0.094 & & -1721.008 & 743.6668 & -2.31 & 0.021 \\
\hline rap & 327.9397 & 80.64635 & 4.07 & 0.000 & & 251.1253 & 66.0294 & 3.80 & 0.000 \\
\hline$i d u$ & 127.0488 & 436.8891 & 0.29 & 0.771 & & -18.1553 & 200.815 & -0.09 & 0.928 \\
\hline$q a c$ & 2.8454 & 0.6319 & 4.50 & 0.000 & & 2.8420 & 0.2862 & 9.93 & 0.000 \\
\hline c & -47468.69 & 38994.11 & -1.22 & 0.225 & & -24717.35 & 17,823 & -1.39 & 0.165 \\
\hline$R^{2}$ & \multicolumn{4}{|l|}{0.43} & \multicolumn{5}{|l|}{0.55} \\
\hline$N$ & \multicolumn{4}{|l|}{598} & \multicolumn{5}{|l|}{598} \\
\hline F-test & & & & & \multirow{2}{*}{\multicolumn{5}{|c|}{ Wald chi2 $(6)=163.32$}} \\
\hline Hausman test & \multicolumn{4}{|c|}{$\begin{array}{l}\mathrm{F}=14.8 \\
\text { Prob }>\text { chi2 }=0.278\end{array}$} & & & & & \\
\hline
\end{tabular}




\section{The map of case study locations}
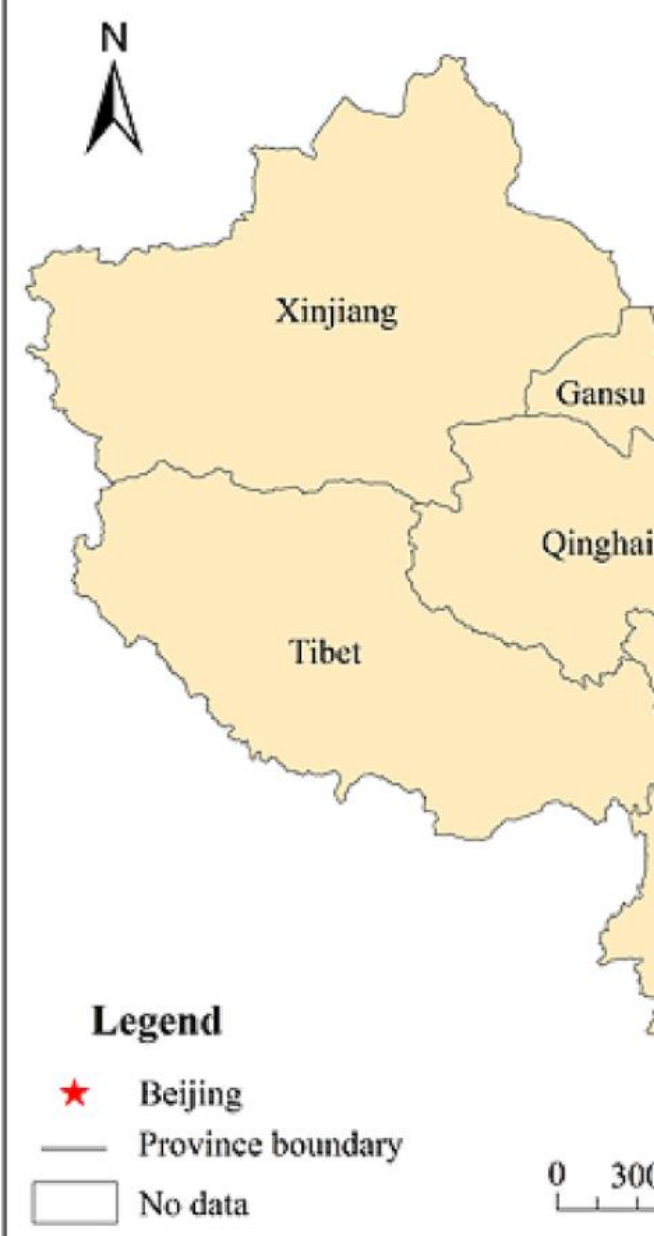

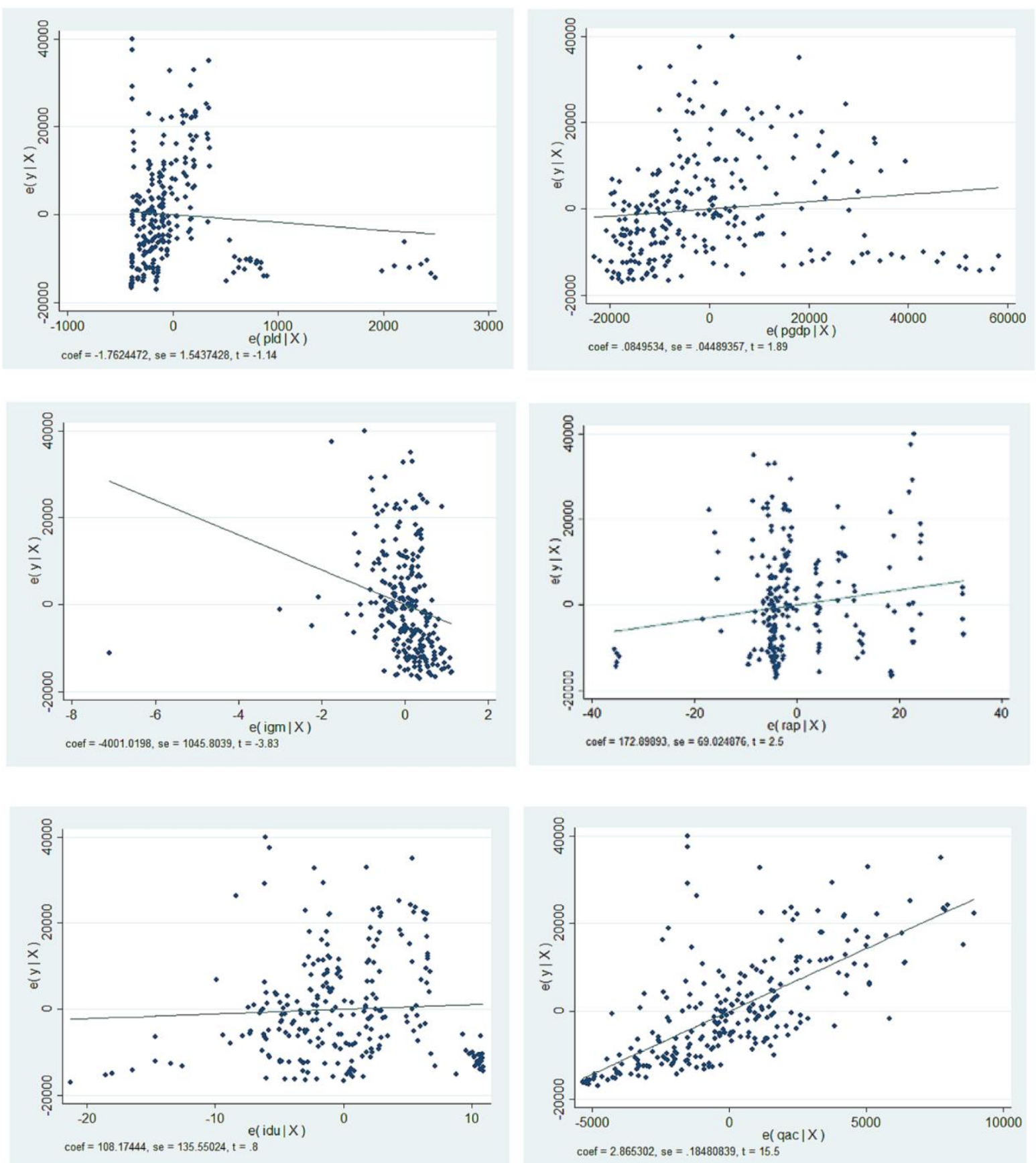

Figure 2. Visual graphs between dependent and independent variables. 


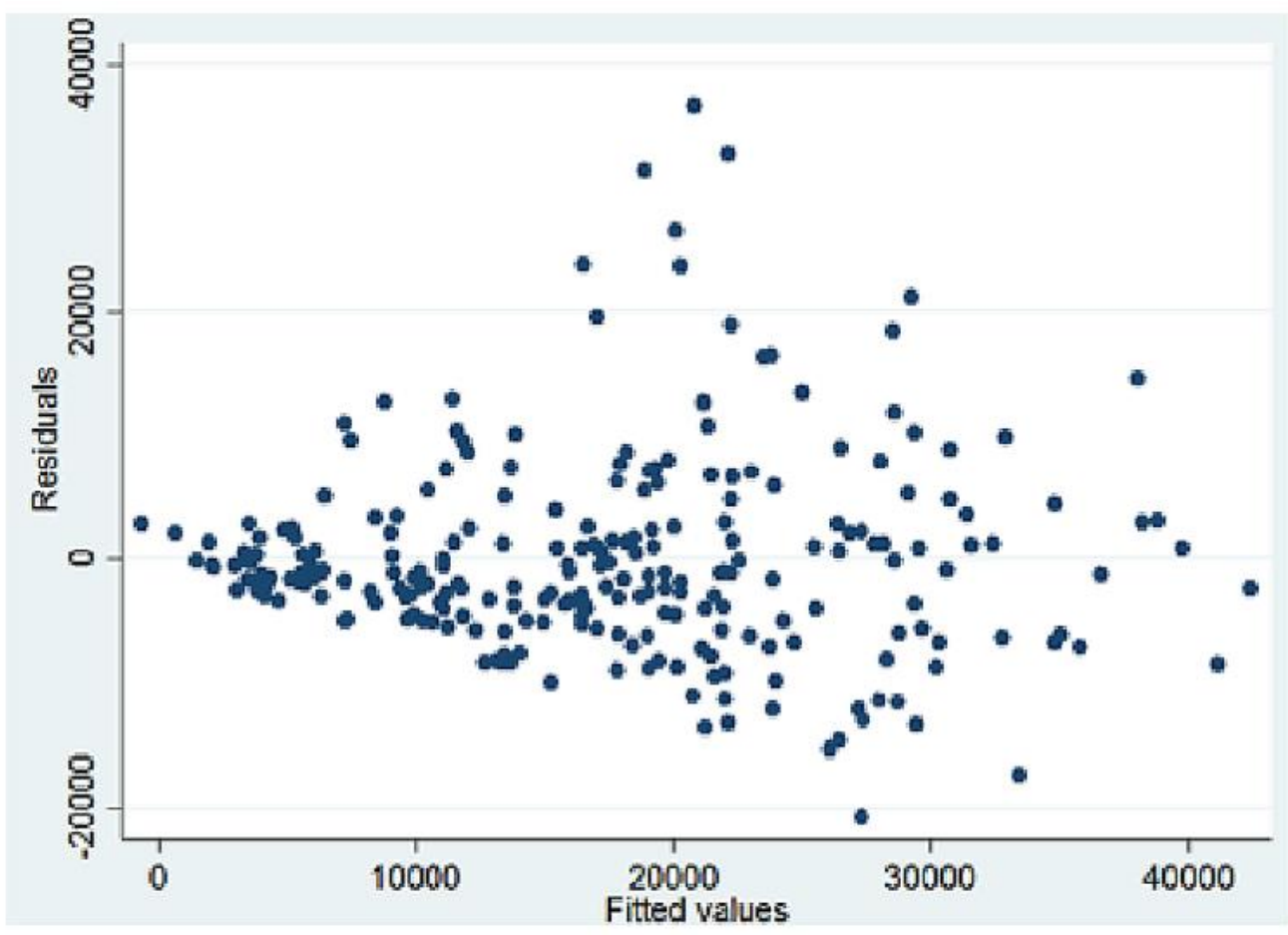

Figure 3. Scatter plot of residuals and fitted values. 


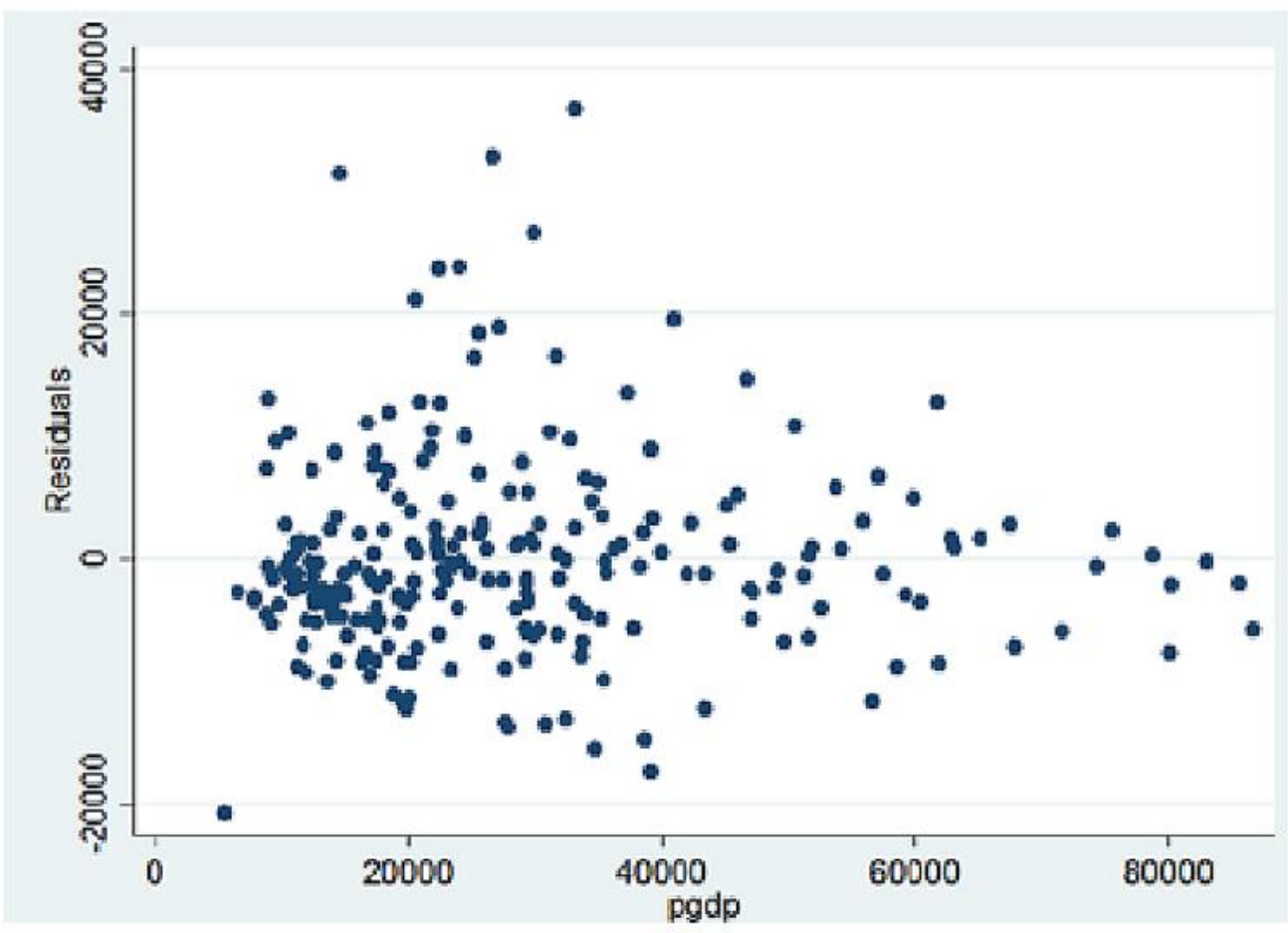

Figure 4. Scatter plot of residuals and $p g d p$. 


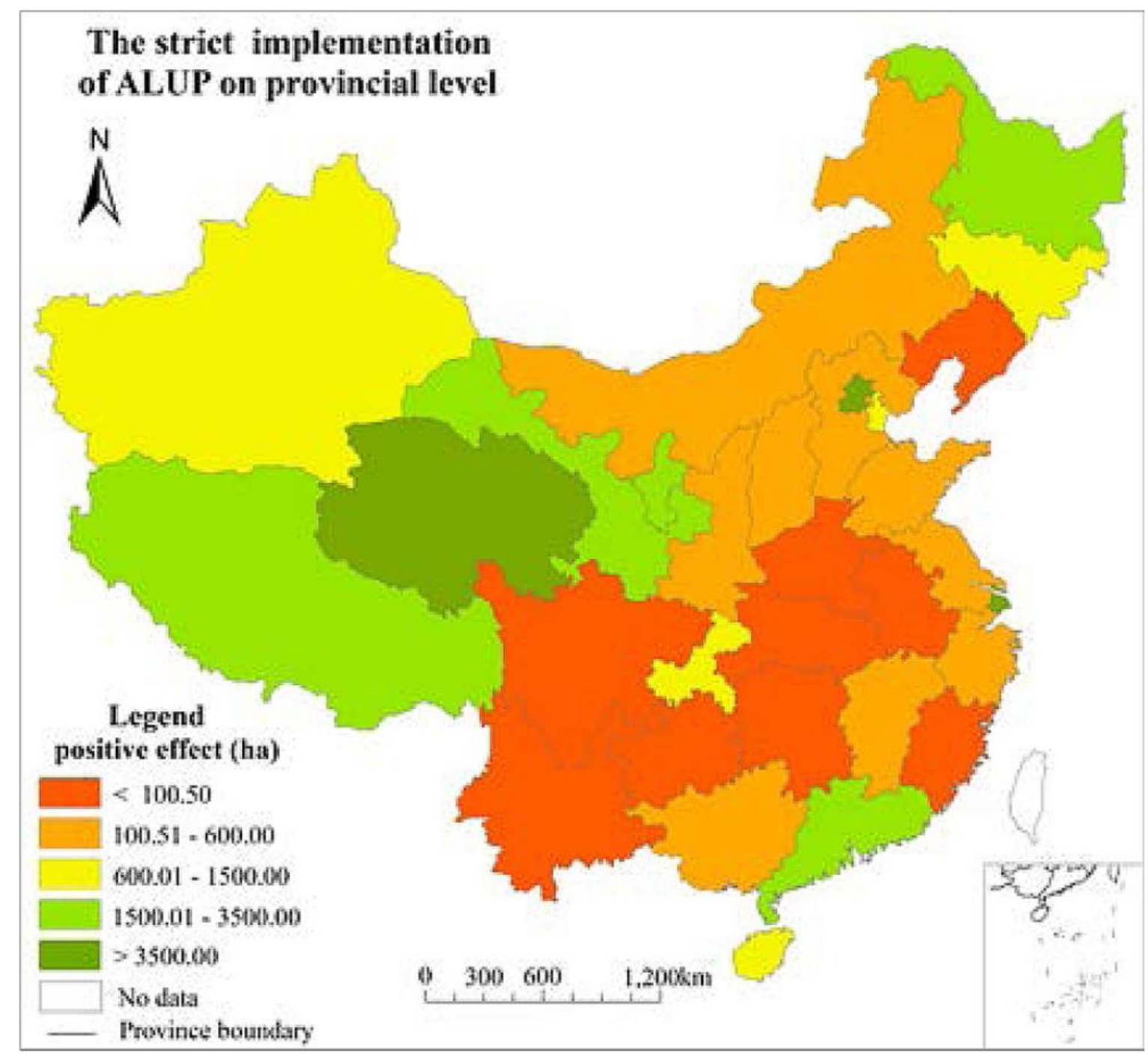

Figure 5. The positive effect of strict implementation of ALUP in China from 2006 to 2013. 


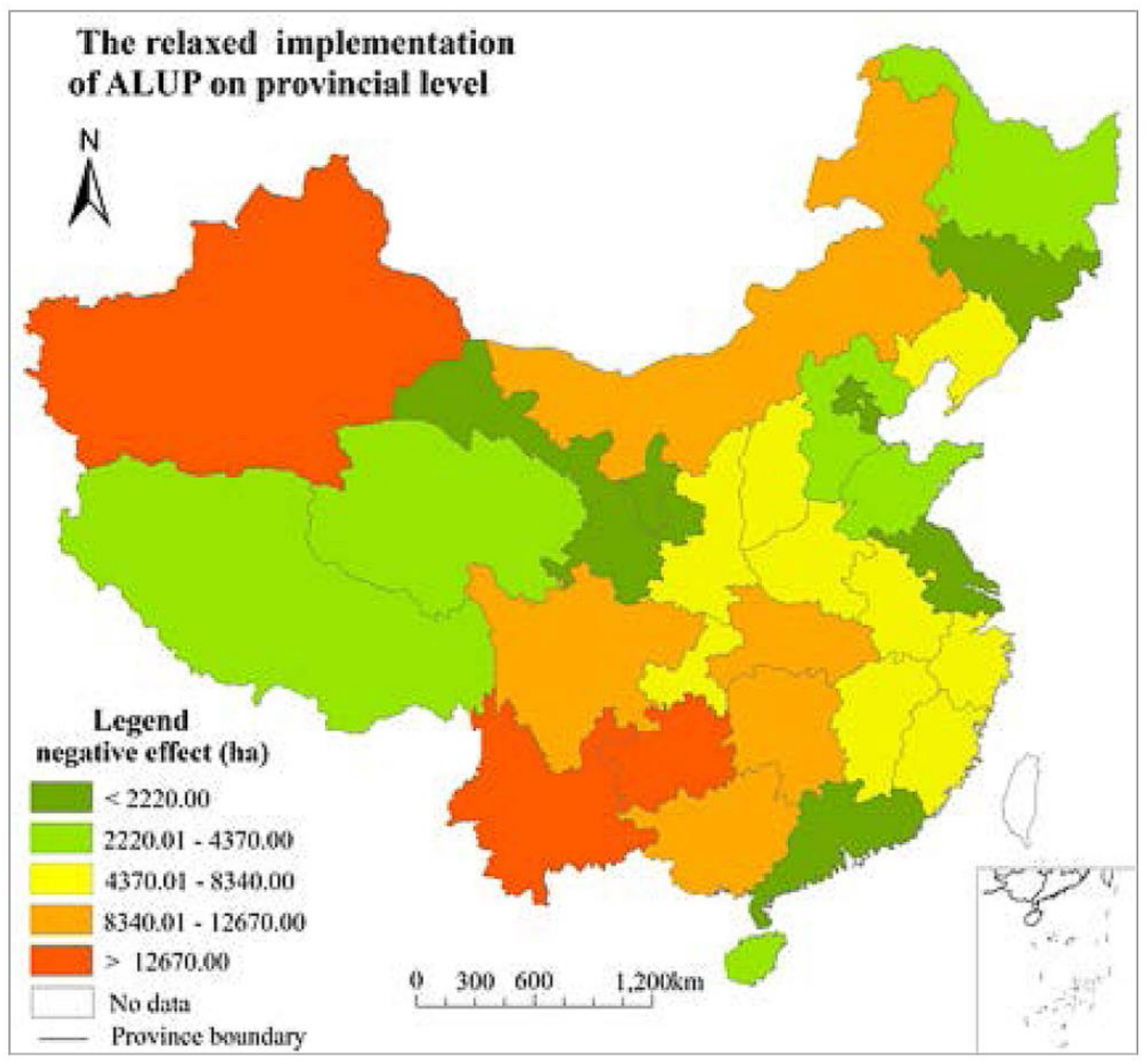

Figure 6. The negative effect of relaxed implementation of ALUP in China from 2006 to 2013. 


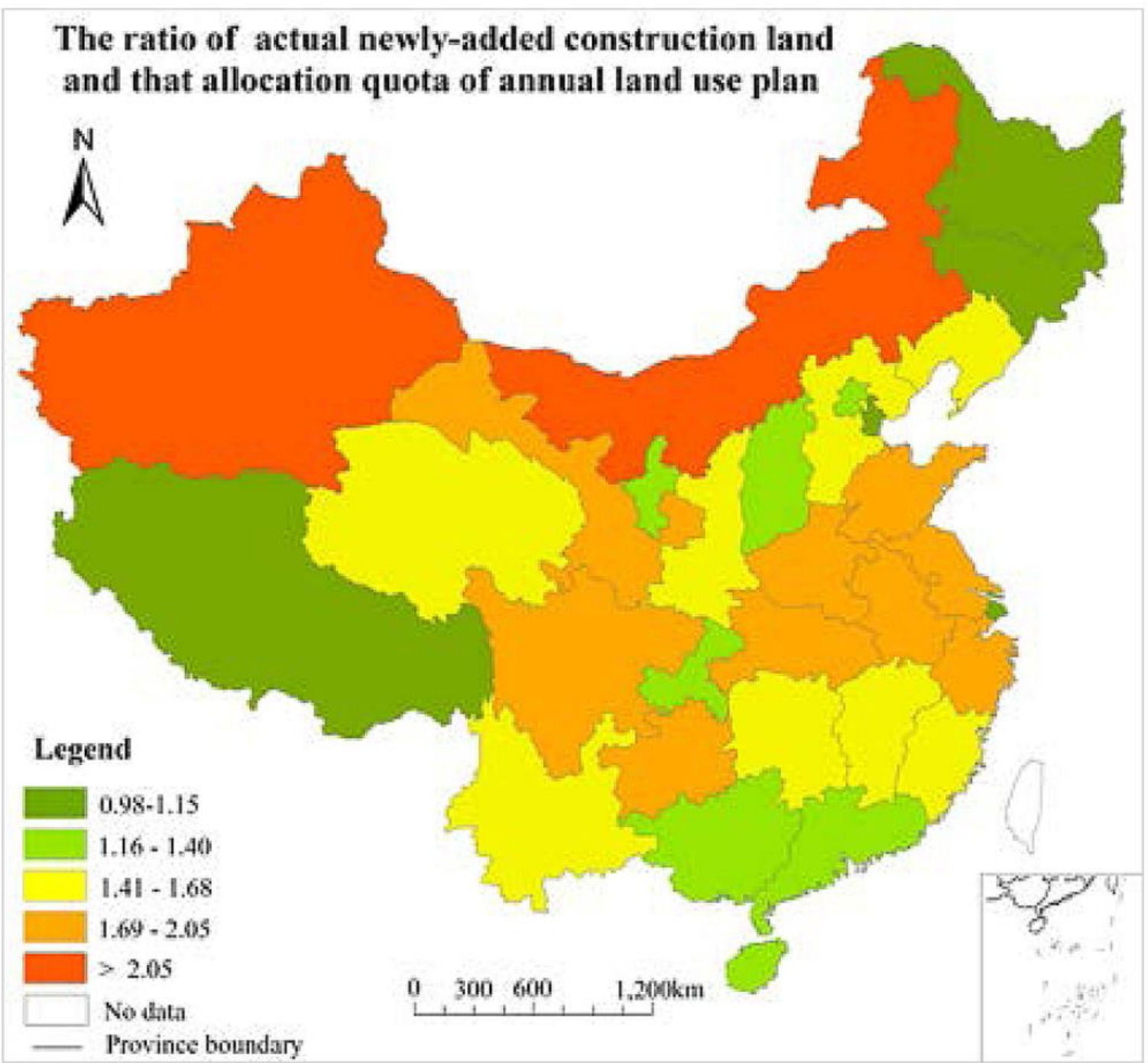

Figure 7. The ratio of actual newly-added construction growth land and that allocation quota of annual land use plan. 


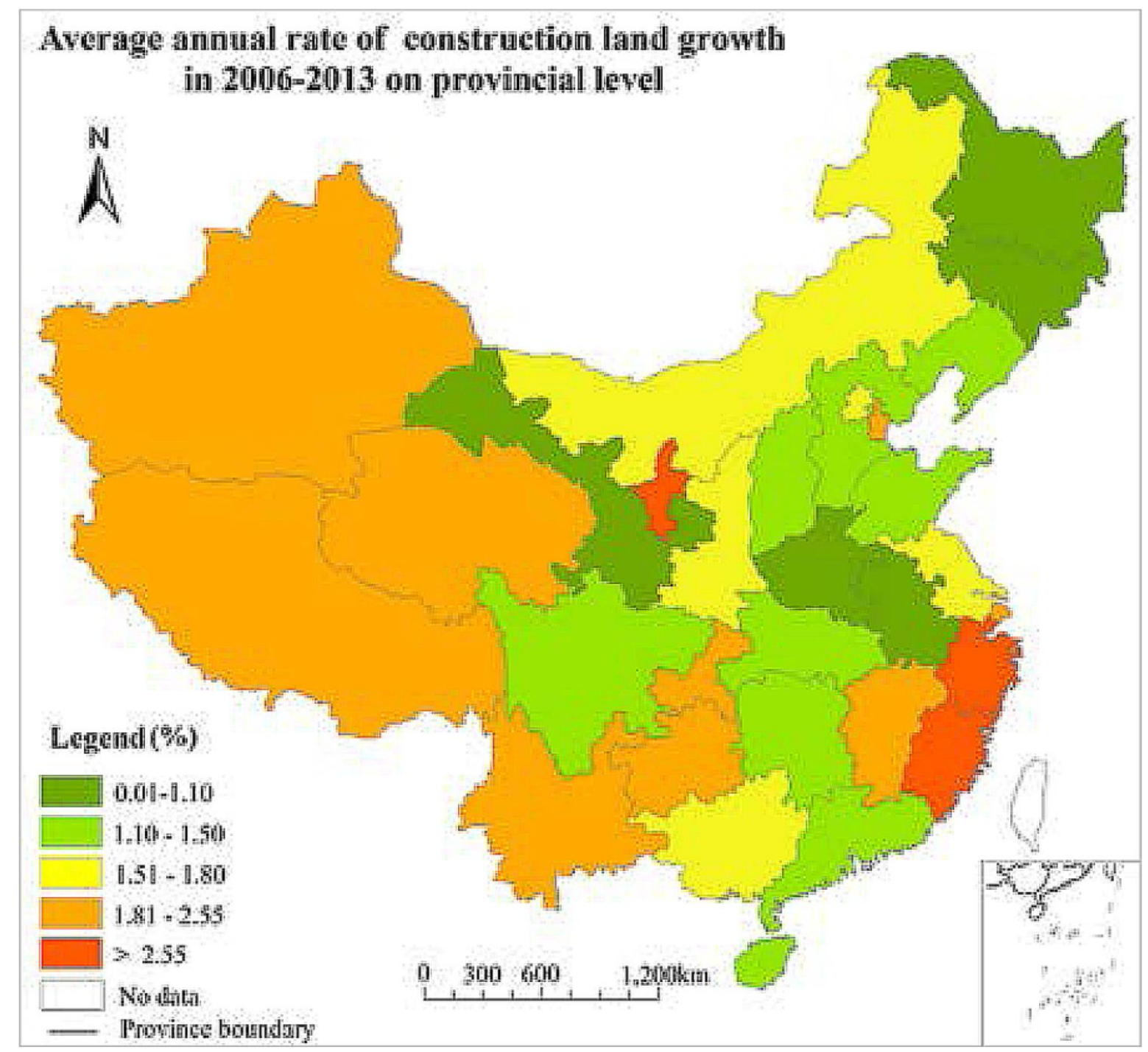

Figure 8. Average annual rate of construction land in 2006-2013 on provincial level. 
- average allocation quota of newly-added construction land in annual land use plan during 2007-2013 average actual newly-added construction land growth during 2007-2013

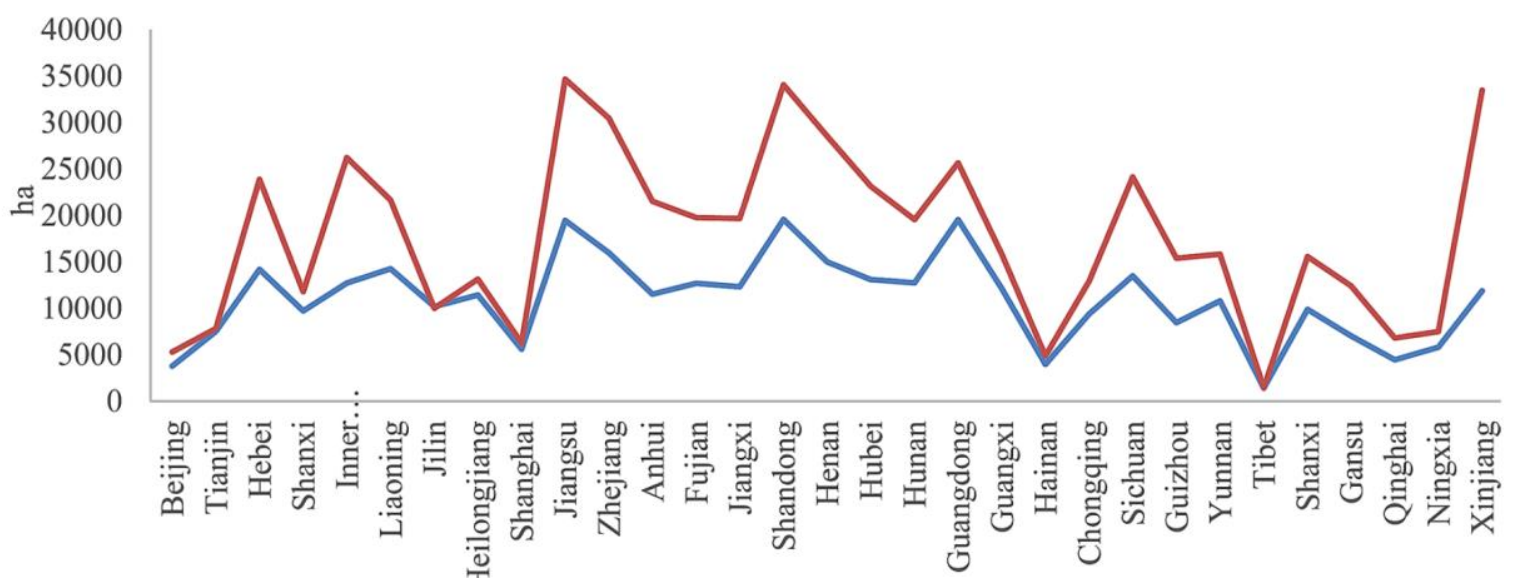

Figure 9. Differences between average actual newly-added construction land growth and that ALUP expected. 